\title{
Influence of the Oxygen Plasma Treatment on Carbon Electrode and Capacity of Supercapacitors
}

\author{
Z. KAVAliaUskas ${ }^{a, b, *}$, L. MARCinAUSKas ${ }^{a, c}$ AND V. VAlincius ${ }^{a}$ \\ ${ }^{a}$ Lithuanian Energy Institute, Plasma Processing Laboratory, Breslaujos 3, LT-4440, Kaunas, Lithuania \\ ${ }^{b}$ Kaunas University of Applied Sciences, Faculty of Technology, Pramones 20, LT-50468, Kaunas, Lithuania \\ ${ }^{c}$ Kaunas University of Technology, Department of Physics, Studentu 50, LT-51368, Kaunas, Lithuania
}

\begin{abstract}
Amorphous carbon electrodes were deposited using atmospheric pressure plasma torch from the mixture of argon and acetylene gases on the stainless steel substrates. The ratio of $\mathrm{Ar} / \mathrm{C}_{2} \mathrm{H}_{2}$ was in the range of $15-55$. The deposited coatings were immersed in low pressure oxygen plasma for $1 \mathrm{~min}$. Scanning electron microscopy images show that when $\mathrm{Ar} / \mathrm{C}_{2} \mathrm{H}_{2}$ ratio increases from 15 to 55, the electrodes surface roughness decreases. The Raman scattering spectroscopy results indicated that the $I_{\mathrm{D}} / I_{\mathrm{G}}$ ratio decreases from 2.04 to 1.35 . It was observed that with the increase of $\mathrm{Ar} / \mathrm{C}_{2} \mathrm{H}_{2}$ ratio from 15 to 55, the capacity of supercapacitor increases from $16 \mathrm{mF}$ to $36 \mathrm{mF}$. The electric capacity of capacitors has increased up to 7 times after their exposure in oxygen plasma.
\end{abstract}

DOI: $10.12693 /$ APhysPolA.125.1316

PACS: 81.15.-z, 81.05.U-, 68.55.J-

\section{Introduction}

Supercapacitors offer a promising alternative approach to meeting the increasing power demands of energy storage systems in general, and of portable (digital) electronic devices in particular $[1,2]$. Supercapacitors are able to store and deliver energy at relatively high rates because the mechanism of energy storage is a simple charge-separation. The vast increases in capacitance achieved by supercapacitors are due to the combination of: (i) an extremely small distance that separates the opposite charges, as defined by the electric double-layer, and (ii) highly porous electrodes that embody very high surface area $[3,4]$.

The power and energy-storage capabilities of these devices are closely linked to the physical and chemical properties of the carbon electrodes. Variety forms of carbon (activated carbon, glassy carbon, and nanotubes) are currently preferred as the electrode materials because they have exceptionally high surface areas, relatively high electronic conductivity, and acceptable cost $[5,6]$. The conductivity, nanopores diameters, surface area, etc. have a major influence on the supercapacitors parameters (capacity, stability voltage, and charge-discharge time). Additionally, the nanopore diameter has a significant effect on capacity $[4,7]$. At a very low pore diameter, capacity decreases, although the surface area can be very high $[8,9]$. Also the capacity of the carbon-structure electrodes can be increased by the formation of various metal oxides, conductive polymers on the top of carbon, or by treatment in plasma [10-13].

In this work, an attempt to increase the capacitance of electric double layer capacitors by modification of the carbon electrodes is made using oxygen plasma.

\footnotetext{
*corresponding author; e-mail: zydrunas@mail.lei.lt
}

\section{Experimental}

The carbon electrodes were deposited from argon-acetylene gas at the atmospheric pressure on the stainless steel 1X18H9T substrates. Argon was used as gas carrier and acetylene as the precursor. Details about this technique are disclosed in Refs. [14, 15]. The ratio of $\mathrm{Ar} / \mathrm{C}_{2} \mathrm{H}_{2}$ varied in the range of $15-55$; the arc voltage was $39 \mathrm{~V}$, the arc current $-25 \mathrm{~A}$, the deposition time - $150 \mathrm{~s}$, and the distance between plasma torch outlet and sample $-0.005 \mathrm{~m}$.

The modification of carbon electrodes was performed by ion irradiation using the magnetron plasma as source of ions accelerated under $500 \mathrm{~V}$ negative bias voltage. The coatings were immersed in the low pressure oxygen plasma for $1 \mathrm{~min}$. The pressure of the oxygen gas was $\approx 1.5 \mathrm{~Pa}$. The magnetron discharge current in the $\mathrm{O}_{2}$ gas was variable in the range 1-20 $\mathrm{mA}$ corresponding to a dissipated power density of $5-500 \mathrm{~W} \mathrm{~cm}^{-2}$.

The properties of carbon coatings were characterized by the Raman scattering (RS) spectroscopy technique using Spectra-Physics Nd:YAG laser $(532 \mathrm{~nm}, 50 \mathrm{~mW}$, spot size $0.32 \mathrm{~mm}$ ). RS were recorded in the Raman shift range from 1000 to $1800 \mathrm{~cm}^{-1}$ and were fitted with Gaussian contours, using least squares fitting software. The electrodes structure was analyzed by X-ray diffraction (XRD) (DRON-UM1, BRUKER D8Advance) with standard Bragg-Brentano focusing in a $5^{\circ}-70^{\circ}$ range using $\mathrm{Cu} K_{\alpha}$ radiation. The surface topography analysis of fabricated carbon layers was carried out using scanning electron microscope (SEM) JSM-5600. Simple supercapacitors have been manufactured, including plasma carbon electrodes. These simple devices are sandwiches of plasma carbon electrodes with an electrolyte, permeating the space between and within them. Aqueous solution (dilute $\mathrm{KOH}$ electrolyte) was used as the electrolyte. To avoid contact between the electrodes, a separator was applied, whereas stainless steel was used as the current collector. 


\section{Results and discussions}

SEM surface views reveal that the coating topography and structure depend on the working gas composition and surface erosion (Fig. 1). When carbon surfaces with maximum acetylene rates were affected by oxygen plasma for $1 \mathrm{~min}$, the surface radicals which have the weakest binding energy with the surface were etched. After the interaction with oxygen plasma, the visible surface structure becomes strictly formed (Fig. 1b).
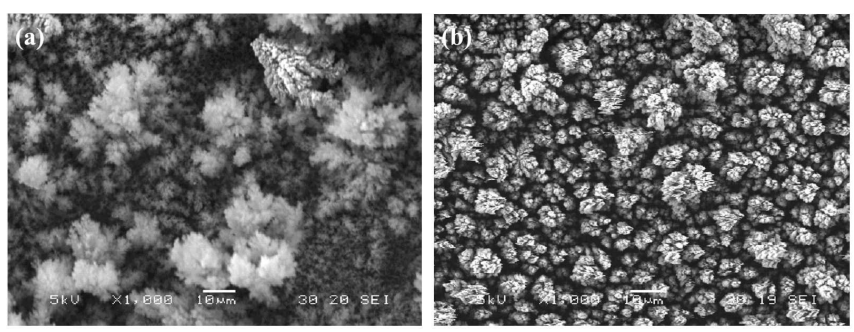

Fig. 1. SEM surface views of carbon coatings after oxygen treatment: (a) $\mathrm{Ar} / \mathrm{C}_{2} \mathrm{H}_{2}=15$, (b) $\mathrm{Ar} / \mathrm{C}_{2} \mathrm{H}_{2}=55$.

The electrode surface consists of microgranules. After the interaction with the active oxygen, the diameter of microgranules increases, decreasing the acetylene quantity in the plasma flow. Meanwhile, very strict structure of microgranules is visible at minimum acetylene gas flows, the diameters are hard to estimate. As it may be noticed, after the interaction with oxygen plasma, the surface becomes rougher when $\mathrm{Ar} / \mathrm{C}_{2} \mathrm{H}_{2}$ ratio decreases. This is because the obtained large diameter granules at low $\mathrm{Ar} / \mathrm{C}_{2} \mathrm{H}_{2}$ ratios in oxygen plasma are etched from all sides, and for this reason their diameter naturally decreases. When $\mathrm{Ar} / \mathrm{C}_{2} \mathrm{H}_{2}$ ratio increases, the obtained microgranules surface becomes smaller in diameter, because they and the inner surface layers are etched; therefore, the small granules disappear, and during that time, new microgranules are formed [14].

The disordered amorphous carbons have two peaks: the so-called graphite $(\mathrm{G})$ peak at $1580 \mathrm{~cm}^{-1}$ and the so-called disordered-induced (D) peak at $1350 \mathrm{~cm}^{-1}$. The spectra of the exposed carbon electrodes consist from two separated almost the same intensity $D$ and $G$ peaks (Fig. 2). It reveals that the carbon layer is amorphous carbon film with mixed structures of $s p^{3}$ and $s p^{2}$ carbon sites. The positions of the $\mathrm{D}$ peak almost do not change the initial position. Meanwhile, the $G$ peak slightly shifted to higher values (from 1586 to $1591 \mathrm{~cm}^{-1}$ ), the full width at half-maximum (FWHM) of the G peak broadened (from 97 up to $110 \mathrm{~cm}^{-1}$ ) and the intensity ratio between the $\mathrm{D}$ and $\mathrm{G}$ peaks $\left(I_{\mathrm{D}} / I_{\mathrm{G}}\right)$ decreases (from 2.04 down to 1.35) with the increase of the $\mathrm{Ar} / \mathrm{C}_{2} \mathrm{H}_{2}$ ratio.

The decrease of the $I_{\mathrm{D}} / I_{\mathrm{G}}$ ratio indicates a higher fraction of the $s p^{3}$ carbon sites. However the relatively high $I_{\mathrm{D}} / I_{\mathrm{G}}$ values indicate domination of the $s p^{2} \mathrm{C}=\mathrm{C}$ sites. The broader $\Delta \mathrm{G}$ indicates higher structural disorder [15].

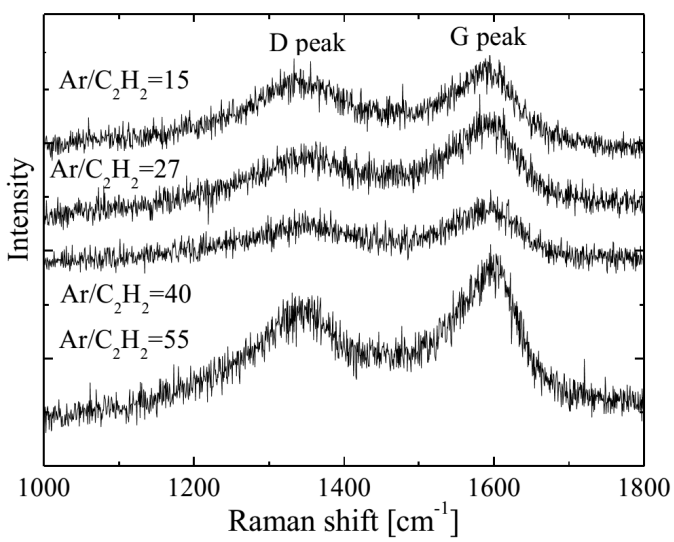

Fig. 2. Comparison of Raman spectra of exposed carbon electrodes.

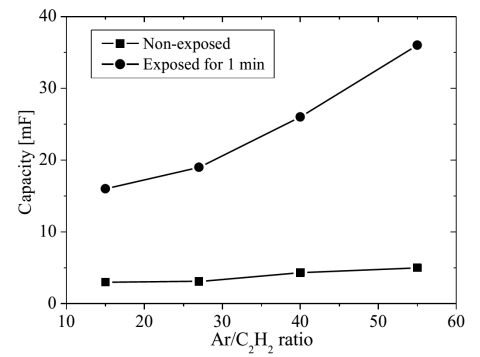

Fig. 3. The dependences of supercapacitor capacity on the ratio of $\mathrm{Ar} / \mathrm{C}_{2} \mathrm{H}_{2}$.

Meanwhile the separation of the D and $G$ bands is attributed to the existing glassy carbon phase in the layer.

RS measurements demonstrated the amorphous graphite-like carbon with glassy carbon phase inserts structure. The XRD measurements confirmed the existence of amorphous carbon phase. The diffraction patterns of the etched carbon electrodes have no diffraction peaks attributed to the crystalline carbon structure.

Investigation of $\mathrm{RS}$ analysis shows that the quantity of $s p^{2} \mathrm{C}=\mathrm{C}$ bonds decreases when $\mathrm{Ar} / \mathrm{C}_{2} \mathrm{H}_{2}$ ratio increases; thus, the quantity of $s p^{3} \mathrm{C}-\mathrm{C}$ bonds increases. The relative integrated intensity ratio $\left(I_{\mathrm{D}} / I_{\mathrm{G}}\right)$ decreases from 2.04 to 1.35. At the same time, the capacity of supercapacitor increases from $16 \mathrm{mF}$ to $36 \mathrm{mF}$ with the increase of the $\mathrm{Ar} / \mathrm{C}_{2} \mathrm{H}_{2}$ ratio from 15 to 55 (Fig. 3). It may be noted that the capacity values of exposed carbon electrodes increases up to 5-7 times compared to non-exposed. Such tendency may be related due to the fact that the prepared carbon electrodes beside $s p^{2}$ and $s p^{3}$ carbon sites have $\mathrm{CH}_{x}$ sites. It is believed that the $\mathrm{CH}_{x}$ sites are etched by the oxygen plasma rather than the carbon sites. The results indicate the increase of capacity when the quantity of $s p^{2}$ bonds decreases $[1,2]$. In this case, the quantity of $s p^{2}$ bonds does not affect the capacity. It may be stated that the dimensions of nanopores or surface area have the main impact on the capacity.

The measurements show that the capacity value is the highest when acetylene quantity in plasma flow is the 
lowest. This suggests that at $\mathrm{Ar} / \mathrm{C}_{2} \mathrm{H}_{2}=55$ after electrodes surface interaction with oxygen plasma, the surface area is the highest [10]. Many authors claim that the sizes of nanopores have a significant influence on the capacity. When the size is smaller than the diameter of electrolyte molecules $(0.5 \mathrm{~nm})$, the formation of double-layer is impossible; thus, pores larger than $0.5 \mathrm{~nm}$ can be eventually accessible electrochemically. As a result, it is difficult to estimate what parameter (area of surface, diameter of nanopores, or quantity of $s p^{2}$ bonds) has the major influence on the capacity of condenser. Meanwhile, the change of $\mathrm{Ar} / \mathrm{C}_{2} \mathrm{H}_{2}$ ratio leads to a slight decrease of stability voltage (changes in $0.4-0.5 \mathrm{~V}$ range). It is well known that the supercapacitors stability voltage is about $0.5-1 \mathrm{~V}$ for the liquid electrolyte, and they do not depend on electrode material [1, 2]. The main reason for the variation of stability voltage is a powerful electric field (about $10^{7} \mathrm{~V} / \mathrm{m}$ ), resulting from charging voltage between the electrodes [2]. It affects the disappearance of the double-layer. On the other hand, the stability level of double electrical layer depends on the inner resistance of supercapacitors. The electric field makes the electric charge carriers to migrate through the electrolyte.

The measured voltamperic dependence of supercapacitors at various $\mathrm{Ar} / \mathrm{C}_{2} \mathrm{H}_{2}$ ratios is presented in Fig. 4a. As the results show, when $\mathrm{Ar} / \mathrm{C}_{2} \mathrm{H}_{2}$ ratio increases from 15 to 55 , the capacitors voltamperic characteristic curves are nearly the same (in range of 0.2-0.4). Increasing $\mathrm{Ar} / \mathrm{C}_{2} \mathrm{H}_{2}$ ratio from 15 to 55 and at voltage range of $0.4-0.55$, the leakage current increases faster. Therefore, at $0.4 \mathrm{~V}$ of voltage the disruption of electrical double-layer begins. The quantity of electric charge through the electrolyte is also increasing. The quantity of $s p^{2}$ bonds has no influence on current level of leakage. Electric charge migrates through the electrolyte because of the strong electric field [2].
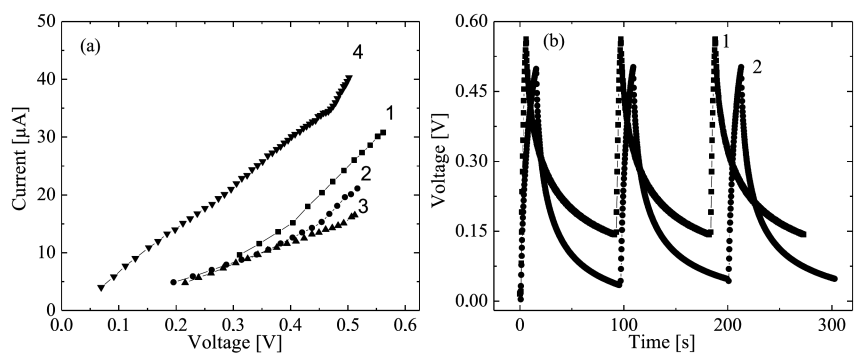

Fig. 4. (a) Voltamperic characteristics of supercapacitors when $\mathrm{Ar} / \mathrm{C}_{2} \mathrm{H}_{2}$ ratio is the following: $1-15$, $2-27,3-40,4-55$ and (b) supercapacitors charge-discharge cycles: $1-\mathrm{Ar} / \mathrm{C}_{2} \mathrm{H}_{2}=15$ and $2-$ $\mathrm{Ar} / \mathrm{C}_{2} \mathrm{H}_{2}=55$.

Measurements of the charge-discharge cycles show appropriate symmetry of the peaks (Fig. 4b); thus, no chemical reactions between the electrolyte and electrode take place. The studies show that the maximum charging voltage is $0.4-0.5 \mathrm{~V}$. This approximately matches the value of supercapacitors stability voltage. The charge-discharge cycle of the capacitors increases from 40 to $65 \mathrm{~s}$, with an increase of $\mathrm{Ar} / \mathrm{C}_{2} \mathrm{H}_{2}$ ratio from 15 to 55 . The longest charge-discharge cycle $(65 \mathrm{~s})$ was obtained for the capacitor with the highest capacity value $(36 \mathrm{mF})$. Therefore, when the capacity of the supercapacitors increases, the characteristic charge-discharge time also increases.

\section{Conclusions}

Three-dimensional structure dominates on the surface of carbon electrodes. The microgranules, with diameter varying from 0.5 to $3 \mu \mathrm{m}$, are visible on the surface. RS investigations show that the quantity of $s p^{2}$ carbon bonds decreases when $\mathrm{Ar} / \mathrm{C}_{2} \mathrm{H}_{2}$ ratio increases. Similarly, the capacity of supercapacitor increases from $16 \mathrm{mF}$ to $36 \mathrm{mF}$ when the quantity of acetylene in the plasma flow decreases. The capacities of the carbon electrodes increase from 5 up to 7 times after treatment in oxygen plasma. The change of $\mathrm{Ar} / \mathrm{C}_{2} \mathrm{H}_{2}$ ratio marginally diminishes the voltage stability. The leakage current increases from 10 to $40 \mu \mathrm{A}$. Meanwhile, the measurements of charge-discharge cycles show a proper symmetry of peaks. The characteristic charging time $(65 \mathrm{~s})$ is the longest when the capacity of supercapacitor is $36 \mathrm{mF}$.

\section{Acknowledgments}

This work was supported by Lithuanian Research Council, Grant No. ATE-02/2012.

\section{References}

[1] R. Kotz, M. Carlen, Electrochim. Acta 45, 2483 (2000).

[2] A.G. Pandolfo, A.F. Hollenkamp, J. Power Sources 157, 11 (2006).

[3] V.V.N. Obreja, Physica E 40, 2596 (2008).

[4] Y.L. Tai, H. Teng, Carbon 42, 2335 (2004).

[5] K. Kierzek, E. Frackowiak, G. Lota, G. Gryglewicz, J. Machnikowski, Electrochim. Acta 49, 515 (2004).

[6] Y.F. Su, Y. Wu, L.Y. Bao, Z.H. Yang, New Carbon Materials 22, 53 (2007).

[7] H. Liu, P. He, Z. Li, Y. Liu, J. Li, Electrochim. Acta 51, 1925 (2006).

[8] H. Li, Y. Li, R. Wang, R. Cao, J. Alloys Comp. 481, 100 (2009).

[9] E. Ito, S. Mozia, M. Okuda, T. Nakano, M. Toyoda, M. Inagaki, New Carbon Mater. 22, 321 (2007).

[10] G. Lota, J. Tyczkowski, R. Kapica, K. Lota, E. Frackowiak, J. Power Sources 22, 195 (2010).

[11] X. Li, B. Wei, Nano Energy 2, 2 (2013).

[12] L. Marcinauskas, Ž. Kavaliauskas, V. Valinčius, J. Mater. Sci. 10, 28 (2012).

[13] Z. Kavaliauaskas, L. Macinauskas, P. Valatkevicius, Acta Phys. Pol. A 119, 253 (2011).

[14] L. Marcinauskas, A. Grigonis, V. Valinčius, J. NonCryst. Solids 355, 1240 (2009).

[15] L. Marcinauskas, A. Grigonis, V. Valinčius, P. Valatkevičius, High Temp. Mater. Proc. 13, 137 (2009). 